\title{
The impact of food allergy on asthma
}

\author{
This article was published in the following Dove Press journal: \\ Journal of Asthma and Allergy \\ 24 July 2010 \\ Number of times this article has been viewed
}

\section{Anupama Kewalramani Mary E Bollinger}

Department of Pediatrics, Division of Pediatric Allergy/Pulmonology, University of Maryland School of Medicine, Baltimore, MD, USA
Correspondence: Anupama Kewalramani University of Maryland School of Medicine, Department of Pediatrics, Division of Allergy/Pulmonology, 737 W. Lombard Street, Suite 3/4, Baltimore, MD 2I20I, USA

Email akewalramani@peds.umaryland.edu
Abstract: Food allergy is a potentially severe immune response to a food or food additive. Although a majority of children will outgrow their food allergies, some may have lifelong issues. Food allergies and other atopic conditions, such as asthma, are increasing in prevalence in Western countries. As such, it is not uncommon to note the co-existence of food allergy and asthma in the same patient. As part of the atopic march, many food allergic patients may develop asthma later in life. Each can adversely affect the other. Food allergic patients with asthma have a higher risk of developing life-threatening food-induced reactions. Although food allergy is not typically an etiology of asthma, an asthmatic patient with food allergy may have higher rates of morbidity and mortality associated with the asthma. Asthma is rarely a manifestation of food allergy alone, but the symptoms can be seen with allergic reactions to foods. There may be evidence to suggest that early childhood environmental factors, such as the mother's and child's diets, factor in the development of asthma; however, the evidence continues to be conflicting. All food allergic patients and their families should be counseled on the management of food allergy and the risk of developing co-morbid asthma.

Keywords: food allergy, diagnosis, treatment, asthma

\section{Introduction, prevalence, and natural history of food allergy}

An adverse food reaction is abnormal response to a food or food additive. Adverse food reactions may involve a physiologic response such as noted with food intolerance or may involve an abnormal immune response as seen with food allergy. Food allergy can involve immunoglobulin E (IgE)-mediated or non-IgE-mediated reactions, and although they may present differently, they are frequently treated similarly. ${ }^{1}$

The prevalence of food allergy has been difficult to estimate at times. A recent meta-analysis of 51 studies demonstrated that the prevalence of self-reported food allergy to cow's milk, egg, peanut, fish, and shellfish varied between $3 \%$ and $35 \%$. However, when the data were analyzed from six studies using oral food challenges (OFCs), the prevalence of food allergy was between 1\% and 10.8\%. ${ }^{2}$ In 2007, three million children under 18 years $(3.9 \%)$ were reported to have a food allergy in the previous 12 months and from 1997 to 2007, the prevalence of reported food allergy actually increased by $18 \%$ among this group. ${ }^{3}$ The most common food allergens in young children are milk $(2.5 \%)$, egg $(1.3 \%)$, peanut $(0.8 \%)$, wheat $(0.4 \%)$, soy $(0.4 \%)$, tree nuts $(0.2 \%)$, fish $(0.1 \%)$, and shellfish $(0.1 \%){ }^{4}$ Initially, it was thought that $85 \%$ of children would outgrow milk, egg, wheat, and soy allergy by 5 years of age; however, 
recent data from a tertiary medical center indicate that this may not always be the case. ${ }^{1}$ Cow's milk allergy was found to resolve in only $19 \%$ of their patients by 4 years of age, $42 \%$ by 8 years, $64 \%$ by 12 years, and $79 \%$ by 16 years. ${ }^{5}$ The group found similar results for the natural history of egg, wheat, and soy allergy. Only 4\% of their patients with egg allergy, $29 \%$ of patients with wheat allergy, and $25 \%$ of patients with soy allergy had resolution of their food allergy by 4 years of age. ${ }^{6-8}$ It was also previously thought that peanut and tree nut allergy were not commonly outgrown, but studies have shown approximately $20 \%$ of children may outgrow peanut allergy and $9 \%$ may outgrow tree nut allergy. ${ }^{1,9,10}$ The most common food allergies in adults are shellfish (2\%), scaled fish $(0.4 \%)$, peanut $(0.6 \%)$, and tree nuts $(0.5 \%)$ which usually persist throughout life. ${ }^{4}$

\section{The diagnosis of food allergy}

The diagnosis of food allergy has remained the same for many years. The diagnostic approach is similar to other conditions and always begins with a detailed food history. The history should focus on whether a food-induced allergic reaction occurred and the possible causal food(s); this may be difficult at times when one considers the issue of hidden ingredients. It is also important to determine the quantity of food ingested, the length of time between the ingestion and development of symptoms, whether similar symptoms have occurred with previous ingestions, whether ancillary factors (ie, exercise, ingestion of aspirin or alcohol) were involved, and when the last reaction occurred. ${ }^{11}$ The history can also assist in determining if the reaction is IgE-mediated, nonIgE-mediated, or neither. IgE-mediated reactions typically have a rapid onset, while non-IgE-mediated (usually T-cell mediated) reactions occur hours to days later. Cell-mediated food allergy reactions usually involve cow's milk and soy allergy, involve the gastrointestinal tract, and primarily affect infants. ${ }^{12}$ IgE-mediated food allergy reactions may affect the skin, gastrointestinal tract, respiratory tract, or even the cardiovascular system and include signs and symptoms such as oral pruritus, facial angioedema, urticaria, vomiting, rhinorrhea, coughing, wheezing, and hypotension. ${ }^{13}$

The physical examination should focus on atopic stigmata, such as eczema, urticaria, and signs and symptoms of asthma or allergic rhinitis; however, the physical is frequently not helpful in these patients. ${ }^{14,15}$

As the history may not always be reliable and the physical may be unrevealing, there are several objective methods that may assist in making a diagnosis of an IgE-mediated food allergy. Skin prick testing to commercially prepared food extracts is a useful screening method for suspected food sensitivity. This form of testing is immediate, reliable, least costly, and best-studied. Testing is done with the suspected commercially prepared food extracts in addition to negative (diluent) and positive (histamine) controls. ${ }^{16}$ Allergens eliciting a wheal response at least $3 \mathrm{~mm}$ greater than the negative control are considered positive. This would indicate a possible allergy to that suspected food, but the response does not necessarily prove that the food is causal as the positive predictive value (PPV) is less than $50 \%{ }^{4}$ A negative skin prick test (SPT) to a food allergen essentially confirms the absence of IgE-mediated allergic reactivity with a negative predictive value greater than $95 \% .{ }^{17}$ With these positive and negative predictive values it is important to use the clinical history to maximize utility of this testing. ${ }^{4}$ The SPT wheal size may be useful in infants younger than 2 years of age, especially for cow's milk, egg, and peanut. Sporik et al found that all patients with an SPT wheal size of at least $7 \mathrm{~mm}$ for egg and $8 \mathrm{~mm}$ for peanut and milk would fail their OFCs. ${ }^{18}$ Commercially prepared extracts are frequently not useful for diagnosing food allergies involving fruits and vegetables because of the lability of the allergen, so most allergists will use the fresh food and apply the SPTs in a similar manner. ${ }^{4}$

In vitro assays to identify food-specific IgE antibodies are also useful modalities in the diagnosis of food allergy. Initially, radioallergosorbent tests were used, but more recently a quantitative measurement of food-specific IgE antibodies (eg, CAP System FEIA; Pharmacia-Upjohn Diagnostics, Bridgewater, NJ) has been utilized and studies have found these serologic tests to be more predictive of symptomatic IgE-mediated food allergy. ${ }^{17}$ Sampson et al demonstrated that increasing concentrations of food-specific IgE correlated with increasing likelihood of clinical reactions. In retrospective and prospective studies, the group was able to establish diagnostic values for milk, egg, peanut, and fish indicating that a patient would be more than $95 \%$ likely to have a reaction. ${ }^{19,20}$ With a retrospective chart review of 604 OFCs, Perry et al established a cutoff level of $2 \mathrm{kU} / \mathrm{L}$ as the food-specific $\mathrm{IgE}$ level for a $50 \%$ pass rate for milk, egg, and peanut. ${ }^{21}$ Unfortunately, undetectable serum food-specific IgE levels may be associated with clinical reactions as well, so even with negative skin prick testing and undetectable food-specific IgE to a food, an OFC may still be required.,22

The double-blind, placebo-controlled food challenge (DBPCFC) is considered the gold standard for the diagnosis of food allergies. The OFC can be open, single-blinded, or double-blinded. All OFCs involve a gradual feeding of the suspected allergen under medical supervision over a certain 
length of time. Once objective signs or persistent subjective complaints are noted (referred to as a failed or positive OFC), the feeding is stopped and treated appropriately. Because there is a risk for anaphylaxis, it is important that the OFC be done with properly trained professionals and with suitable medications and equipment to treat severe reactions. Open or single-blind OFCs are frequently used to screen for reactions, but the DBPCFC is the preferred method for diagnosis as bias on the part of the subject and observer are removed. ${ }^{23}$ The OFC is time-consuming and has the potential to induce a severe reaction, so if a patient has a history consistent with a food allergy and the SPT and/or serum food-specific IgE is also consistent, the OFC can be deferred.

\section{The impact of food allergy on asthma}

As noted previously, the prevalence of food allergy has been increasing as has the prevalence of other atopic conditions, such as asthma. Approximately 38.4 million Americans have been diagnosed with asthma by a health care professional during their lifetime and an estimated 300 million people worldwide suffer from asthma, with 250,000 annual deaths. ${ }^{24,25}$ The prevalence of asthma increased 75\% from 1980-1994 and asthma rates in children under the age of 5 years increased more than $160 \%$ from $1980-1994 .{ }^{26}$ It is currently estimated that by 2025 , the number of people with asthma will grow by 100 million. ${ }^{25}$

Food allergy and asthma frequently co-exist, but it is difficult to ascertain the true prevalence. Children with food allergy are more than two to four times as likely to have other atopic conditions such as asthma, eczema, or respiratory allergy compared to children without food allergies. In $2007,29 \%$ of children with food allergy also had asthma and approximately $8 \%$ of children with asthma had food allergy based on a study in 1980 by Oehling et al.,27 From the National Cooperative Inner City Asthma Study (NCICAS), 454 random serum samples from children ages four to nine years were evaluated for specific IgE to egg, milk, soy, peanut, wheat, and fish. Four percent demonstrated specific IgE levels $>95 \%$ PPV for clinical reactivity to at least one food while $45 \%$ of patients had evidence of sensitization. Unfortunately, because this study used anonymous serum samples, it is unclear if these patients actually had a diagnosis of or symptoms related to food allergy. ${ }^{28}$

Studies have suggested that eczema and food allergen sensitization is a risk factor for the development of asthma and the relationship of these atopic conditions is frequently referred to as the "atopic march." 29 Priftis et al evaluated 69 children over the age of 7 years who, during their first three years of life, had been diagnosed in their clinic with egg and/or fish allergy. Over $40 \%$ of patients reported current asthma symptoms based on the questionnaire used by the International Study of Asthma and Allergies in Children. All patients had normal pulmonary function testing, but there was a significantly increased frequency of positive responses on methacholine challenge when compared to aeroallergen-sensitized children without a history of food allergy. ${ }^{30}$ The Isle of Wight study was a larger study involving a prospective whole-population birth cohort study. They found egg allergy in infancy correlated with development of respiratory allergic symptoms and aeroallergen sensitization by the age of 4 years. At 4 years of age, respiratory allergic disorders were noted to be more common among the egg-allergic children than eczema or food allergy. In contrast, allergy to cow's milk did not significantly increase the incidence of asthma. The PPV of egg allergy for asthma was $40 \% .{ }^{31}$ A study by Schroeder et al of 271 children 6 years and older and 296 children younger than 6 years found similar results. A diagnosis of current asthma was based on parental report of physician diagnosis and reported asthma symptoms in the previous year. Symptomatic food allergy was significantly associated with asthma in the older children with an odds ratio (OR) of 4.9 (95\% confidence interval [CI]: 2.5-9.5) and OR of 5.3 in younger children (95\% CI: 1.7-16.2). Additionally, the odds of having asthma increased with increasing number of food allergies. The time from age of onset of food allergy and age of asthma onset was also evaluated. In the older age group, the median age of the onset of asthma was 5 years. In the younger children, the median age of asthma onset was 2.3 years. ${ }^{32}$ The German Infant Nutritional Intervention (GINI) study was a multicenter, double-blind, randomized intervention study that enrolled 2,252 infants with a single (one parent and/or sibling) or biparental history of atopy to examine the preventive effect of different hydrolyzed infant formulas on the development of atopic diseases. As part of the study almost 1,300 children were evaluated at 12 months of age and underwent prick skin testing to food allergens and aeroallergens and were then followed until 6 years of age. They administered questionnaires to the families at $1,2,3,4$, and 6 years of age to determine if the child had developed asthma. They found that early food sensitization significantly increased the relative risk of developing asthma by six years of age (OR 3.93, 95\% CI: 1.95-7.91), but that early aeroallergen sensitization had an even greater risk (OR 4.36, 95\% CI: 1.38-13.78). ${ }^{33}$ 
Asthma may actually be a risk factor for fatal or nearfatal anaphylaxis to foods. In a survey of six fatal and seven near-fatal anaphylactic reactions to food in children and adolescents over a 14 month period, all patients had asthma and in all but one, the asthma was considered wellcontrolled with medications. However, two of the patients with fatal reactions had been taking oral corticosteroids within one month of the reaction. Additionally, two patients with fatal reactions and one with a near-fatal reaction had serious wheezing in the two weeks prior to the reactions. All of the patients developed respiratory symptoms during their reactions. ${ }^{34}$ After this study, a reporting registry, through the American Academy of Allergy, Asthma, and Immunology with the assistance of the Food Allergy and Anaphylaxis Network, was established. Bock et al analyzed 32 fatal cases of food-induced anaphylactic reactions reported to the registry from 1994-1999, and another 31 fatalities reported from 2001-2006. The ages ranged from 2 to 50 years and $56 \%$ of the patients were male. Reactions to peanut and tree nuts accounted for most of the deaths. Of the 45 patients for whom data on asthma were known, 44 had active asthma. ${ }^{35,36}$ In a study to determine risk factors for the administration of repeated doses of epinephrine in food-induced anaphylaxis, Jarvinen et al administered a questionnaire to parents or caregivers of food-allergic children. They found that subjects treated with multiple doses of epinephrine more often reported asthma at the time of survey completion. ${ }^{37}$

Food allergy may be a risk factor for asthma morbidity and mortality in childhood as well. In NCICAS, children with asthma who were sensitized to at least one food had a higher rate of hospitalization and required more steroid medications. ${ }^{28}$ Simpson et al performed a retrospective chart review on 201 patients, aged 3 months to 14 years, with a diagnosis of asthma and divided the group into those with a history of food allergy and those without. Milk and peanut allergy were significantly associated with increased number of hospitalizations due to asthma. Milk allergy was also associated with requiring more courses of systemic steroids. Having more than one food allergy was associated with more asthma hospitalizations and oral steroid courses. Egg or fish allergy were not associated with increased asthma morbidity. ${ }^{38}$ Roberts et al recruited children aged 1 to 16 years ventilated in the Pediatric Intensive Care Unit (PICU) for an acute asthma exacerbation. Controls were selected from all patients seen in the Emergency Department with an asthma exacerbation and were matched to the cases by gender, ethnicity, and age. All subjects were questioned about food allergies and underwent either skin prick testing or specific IgE serologic testing for environmental and food allergens. Food allergy was found to be an independent risk factor for life-threatening asthma with an adjusted OR of 5.89 (95\% CI: 1.06-32.61). ${ }^{39}$ A retrospective chart review of asthmatic children at the Cleveland Clinic admitted to the PICU or nursing floor with an exacerbation and asthmatic children seen in an ambulatory clinic was conducted. The group reviewed demographic and clinical data and found that of the 288 medical records reviewed, $13 \%$ (38/288) of the records contained documentation of at least one food allergy. Children admitted to the PICU were 3.3 times more likely to have at least one food allergy than those admitted to the regular nursing floor and 7.4 times more likely than the children seen in the clinic. ${ }^{40}$

Although cough and wheeze are recognized pulmonary manifestations of food-induced IgE-mediated reactions, they are usually accompanied by other symptoms and it is rare to see these as the only manifestations when the inciting food in ingested. Bock et al performed 1,014 DBPCFCs on 480 children aged 3 months to 19 years. There were 245 challenges that resulted in symptoms. Cutaneous and gastrointestinal symptoms accounted for the majority of reactions. Of the 245 positive food challenges, wheezing was the sole manifestation in only four children (1.6\%). Wheezing, with either cutaneous or gastrointestinal manifestations, occurred in $36(7.5 \%)$ of the 480 children. ${ }^{41}$

Studies have demonstrated that lower respiratory symptoms may be seen in food-induced allergic reactions in asthma patients, but asthma is rarely an isolated manifestation of food allergy. Onorato et al studied 300 asthma patients aged seven months to 80 years in a respiratory clinic. Twenty-five (12\%) of these patients were suspected of having food-induced asthma, but only six had wheezing on a DBPCFC and interestingly all six were children. Hence, although adults may have reported asthma related symptoms during ingestion of certain foods, it was less likely to see those symptoms with food challenges. ${ }^{42}$ Novembre et al evaluated 140 asthmatic children aged two to nine years and using DBPCFCs were able to demonstrate respiratory symptoms in only 13 of $140(9.2 \%)$ children. Only eight (5.7\%) had immediate- or delayed-onset asthmatic reactions; but of these eight, asthma was the sole symptom in only one patient. ${ }^{43}$ James et al performed DBPCFCs on 320 patients with atopic dermatitis to characterize respiratory symptoms seen in positive DBPCFCs. Fifty-five percent of patients had co-morbid asthma. Thirty-four (17\%) of the 205 children who failed the challenge developed objective wheezing, and 
all but three of these had a previous history of asthma. The most common foods inducing these reactions were egg and milk. A subset of 88 patients also underwent spirometry prior to, during and after the challenges. Of the 88 who performed spirometry, 13 (15\%) experienced lower airway symptoms, but only six demonstrated a greater than $20 \%$ decrease from baseline forced expiratory volume in one second $\left(\mathrm{FEV}_{1}\right)$. Although respiratory symptoms were frequently noted in this group, it was rare to observe significant bronchopulmonary obstruction. Also, all six patients demonstrated other signs and symptoms of food allergy including cutaneous and/or gastrointestinal signs and symptoms. ${ }^{44}$ The same group measured airway hyperresponsiveness with methacholine challenges prior to the start of the DBPCFC and four hours after completion of the challenge. Thirty-eight DBPCFCs were performed on 26 asthmatic patients with food allergy. This study demonstrated that food-induced allergic reactions during DBPCFCs could increase airway reactivity in a subset of asthmatic patients without inciting an asthma exacerbation. There were 22 positive food challenges resulting in symptoms, of which 12 challenges in 12 subjects resulted in chest symptoms including cough, chest tightness, and/or wheeze. There was a decrease in the FEV by $15 \%$ or more in only one of these patients, but another was unable to perform spirometry due to the severity of the reaction. A significant increase in airway hyperresponsiveness (defined as a decrease in the $\mathrm{FEV}_{1}$ by $20 \%$ ) was observed after seven challenges. A significant increase in airway hyperresponsiveness was also seen in one patient with a positive DBPCFC without chest symptoms and in one patient who had a negative DBPCFC. ${ }^{45}$

Spirometry has also been monitored in adults undergoing food challenges to cow's milk. Twenty subjects aged 18 to 65 years with asthma were recruited. Ten subjects believed that their asthma worsened after milk ingestion while the other $10 \mathrm{did}$ not. None of the patients had positive skin prick testing with cow's milk extract, but underwent a double-blind, placebo-controlled trial. Both $\mathrm{FEV}_{1}$ and peak expiratory flow (PEF) were measured prior to, during, and after the challenge. Although nine subjects had at least a 15\% decrease in their $\mathrm{FEV}_{1}$ or PEF during the active or placebo challenges, there was no statistically significant difference in group means in the $\mathrm{FEV}_{1}$ and PEF between the active or placebo challenges. ${ }^{46}$

Although ingestion of food allergens is rarely associated with respiratory symptoms, inhalation of food allergens can induce respiratory symptoms. Occupational asthma refers to those workers who are sensitized and then develop symptoms related to workplace exposures. Approximately $9 \%-15 \%$ of adult asthma can be attributed to workplace exposures, but more recent data indicate that $25 \%$ or more of new-onset asthma may be related to occupational asthma. ${ }^{47}$ The most common form is baker's asthma with an incidence of between 1-10 cases in 1,000 bakery workers. Any worker in the bakery can develop this disease and the main inciting agents are cereal flours (wheat, rye, barley) and enzymes. ${ }^{48}$ A longitudinal study of 287 apprentice bakers from three country districts of Poland found that the incidence of work-related chest symptoms (dyspnea, wheezing, and cough) was $4.2 \%$ in the first year and $8.6 \%$ in the second year of exposure. They also found that sensitization to occupational allergens frequently preceded the asthma symptoms. ${ }^{49}$

In children and adults, nonoccupational exposures to airborne food particles can also elicit respiratory reactions, usually during cooking or manipulation of the food, especially seafood. ${ }^{50}$ Allergic reactions associated with airborne fish particles have been reported in patients with fish allergy. In one study, of the 197 children fish-allergic patients evaluated, 21 reported symptoms after exposure to fish odors or fumes. With inhalation, nine patients reported only respiratory symptoms (mainly wheezing), nine reported only cutaneous symptoms and three reported both. Twenty patients were exposed to the fumes from the boiling or frying of the fish. ${ }^{51}$ There is frequently concern for allergic reactions to food, especially peanuts, on commercial airlines since peanut can be detected in their ventilation filtering systems. ${ }^{52}$ Sicherer et al interviewed patients in the National Registry of Peanut and Tree Nut Allergy who reported symptoms of peanut allergy while on an airplane. Of the 35 subjects, 14 reported symptoms by inhalation. ${ }^{53}$

\section{Effect of diet on asthma development and severity}

The increasing prevalence of asthma and other atopic conditions have placed a high burden on health care resources. In 2004, asthma accounted for approximately 1.8 million Emergency Department visits, 14.7 million physician office visits, and almost 500,000 hospitalizations. It also accounts for over 10 million missed work days for adults annually. ${ }^{54}$ The annual economic cost of asthma is $\$ 20.7$ billion. Direct costs make up $\$ 15.6$ billion of that total, and indirect costs such as lost productivity add another $\$ 5.1$ billion. ${ }^{24}$ With this increasing health care burden, there has been more interest in primary and/or secondary prevention of allergic disease such as asthma. 


\section{Maternal diet and asthma development in children}

Although atopic diseases have a clear genetic basis, environmental factors, including maternal and infant nutrition, may also have an influence on their development. The fetus is capable of mounting an immune response to food allergens so some physicians have attempted to decrease the risk of developing food allergy and other atopic conditions by restricting the diet of pregnant mothers..$^{55}$ A 2009 Cochrane review evaluated whether maternal dietary allergen avoidance during pregnancy or lactation would prevent development of atopic conditions in the child. They included all randomized or quasi-randomized comparisons of maternal dietary antigen avoidance prescribed to pregnant or lactating women. They actually found that restricted diet during pregnancy was associated with a slightly but statistically significantly lower mean gestational weight gain, a non-significantly higher risk of preterm birth, and a non-significant reduction in mean birth weight and found no protective effect on atopic diseases. ${ }^{56} \mathrm{In}$ a study by Willers et al, there were no consistent associations between the maternal intake of milk, egg, or fish in the last month of pregnancy and development of asthma by 8 years of age; however, daily nut consumption during pregnancy was significantly associated with childhood wheeze, wheeze without respiratory infection, steroid use, and doctor-diagnosed asthma. ${ }^{57}$ In 2008, the American Academy of Pediatrics (AAP) suggested that there was not enough evidence to recommend maternal dietary restrictions during pregnancy and lactation to modify the development of atopic conditions. ${ }^{58}$

Vitamin D deficiency has received a significant amount of attention recently and has been recognized in many countries, even those with significant sun exposure. Pregnant women and lactating mothers are at significant risk given the requirements for vitamin D by the fetus and neonate. ${ }^{59}$ Some investigations have focused on maternal vitamin $\mathrm{D}$ intake and the risk for the development of asthma and allergies. Camargo et al evaluated 1,194 mother-child pairs as part of Project Viva, a prospective pre-birth cohort study in Massachusetts. The researchers assessed maternal intake of vitamin D during pregnancy by using a validated food-frequency questionnaire. The primary outcome was recurrent wheeze assessed at the child's 1-year visit and annually thereafter until 3 years of age. By 3 years of age, 186 children (16\%) had recurrent wheeze. A higher maternal intake of vitamin D during pregnancy was associated with a lower risk of recurrent wheeze.$^{60} \mathrm{In}$ contrast to this study, Wjst et al hypothesized that the recommendation of additional vitamin $\mathrm{D}$ intake actually paralleled the rising prevalence of allergic disorders. ${ }^{61}$ Gale et al concurred with that hypothesis. Their study involved 466 pregnant women whose children were evaluated at birth, nine months and at nine years. They were able to obtain serum samples to measure the mother's 25-hydroxy vitamin D concentrations in late pregnancy. Exposure to high maternal concentrations of vitamin $\mathrm{D}(>75 \mathrm{nmol} / \mathrm{L})$ was associated with an increased risk of reported asthma at nine years compared with children whose maternal concentrations were less than $30 \mathrm{nmol} / \mathrm{L}$ (OR 5.40, 95\% CI: 1.09-26.65). Unfortunately, by 9 years of age, the group had a large loss to follow-up with only 178 children. ${ }^{62}$ Elucidating the role of maternal vitamin D intake in the development of asthma will require further studies.

\section{Breastfeeding and asthma development}

The protective effects of breastfeeding on development of atopic conditions have consistently been promoted by pediatricians and allergists. In 2000, the AAP recommended mothers of high risk infants (those with a family history of atopy in both parents or one parent and a sibling) to eliminate peanuts and tree nuts and to consider eliminating eggs, cow's milk, and fish from their diets while nursing. ${ }^{63}$ However, studies related to this topic provide conflicting data as well. Results from a prospective, population-based cohort study investigated whether prolonged breast-feeding was associated with a reduced risk of asthma during the first four years of life. Asthma was defined as having at least four episodes of wheezing during the previous 12 months or at least one episode of wheezing while the child was receiving inhaled steroids. At the age of 4 years, children who had been exclusively breastfed for four months or more exhibited a reduced risk of asthma compared with children breastfed for less than four months. The beneficial effects of breastfeeding were more pronounced in children who did not have a parent with atopic disease than in those with an atopic parent. ${ }^{64}$ Gdalevich et al conducted a meta-analysis of 12 prospective studies that evaluated the association between exclusive breast-feeding during the first three months after birth and the development of asthma between 2 and 5 years of age. They found an overall protective effect of exclusive breastfeeding for 3 months with an OR of 0.70 (95\% CI: $0.60-0.81$ ) on the development of asthma in childhood. In this study, the effect seemed to be more pronounced in families with an atopic history. ${ }^{65}$

Matheson et al actually assessed the relationship between breastfeeding and atopic disorders in a population-based cohort (The Tasmanian Asthma Study) that they followed into middle age. Asthma presence or absence was based on answers to a questionnaire which was completed by a parent when the subject was 7 and 13 years of age, and then completed by the 
subject at 34 and 44 years of age. Interestingly, in subjects who had a mother with an atopic disease, breastfeeding was protective against asthma at seven years (OR 0.75, 95\% CI: $0.58-0.97)$, but this trend actually reversed at age 14 years at which time breastfeeding became a risk factor for asthma (OR 1.46, 95\% CI: 1.02-2.07). This persisted at 32 and 44 years of age. No association between breastfeeding and the development of asthma was noted in subjects whose mothers did not have atopy. ${ }^{66}$ In New Zealand, a longitudinal study of a population-based birth cohort also found breastfeeding for four or more weeks significantly increased the risk of asthma in mid to later childhood. The cohort consisted of 1,037 children from the general population of whom 504 were breast-fed for four weeks or longer. The children were evaluated every two to five years from 9 to 26 years of age with respiratory questionnaires, spirometry, methacholine challenges, and skin prick testing to allergens. More children who were breastfed were diagnosed with asthma, had current asthma, and had current wheeze at each assessment between 9 and 26 years of age. Also, children who were breastfed were more likely to have current asthma with airway hyperresponsiveness (defined as a fall of $\mathrm{FEV}_{1}$ by $20 \%$ or more after inhalation of methacholine in a concentration of $8 \mathrm{~g} / \mathrm{L}$ or less). ${ }^{67}$ More recently, Elliott et al used data from the Avon Longitudinal Study of Parents and Children which was a large prospective birth cohort in the United Kingdom (UK). They found that breastfeeding was protective for wheeze in the first three years of life, but that did not extend for wheeze or bronchial hyperresponsiveness at ages 7 and 8 years. ${ }^{68}$ Based on these and other studies, there may be evidence that exclusive breastfeeding for at least three months of life is protective against early wheezing, but the data is not convincing for preventing asthma beyond six years of life and in fact, may increase the risk. ${ }^{58}$

\section{Hydrolyzed formulas and asthma development}

The use of partially or extensively hydrolyzed formulas in infants for the prevention of atopic diseases has also been investigated. Oldaeus et al compared the incidence and severity of atopic disease and allergic sensitization during the first 18 months of life in infants at risk who were fed an extensively hydrolyzed cow's milk formula, a partially hydrolyzed formula, or a regular cow's milk formula from the start of weaning until nine months of age. All infants had a family history of atopy. The cumulative incidence of wheezing episodes in the first 18 months of life was significantly higher in the group fed regular cow's milk than in the group fed the extensively hydrolyzed formula. Unfortunately, the study did not follow these infants for an extended period to evaluate whether this apparent protective effect of hydrolyzed formulas persisted. ${ }^{69}$ In the GINI study, infants who received formula were randomized into partially hydrolyzed whey-based (pHF-W) formula, an extensively hydrolyzed whey-based (eHF-W) formula, an extensively hydrolyzed casein-based (eHF-C) formula or a conventional cow's milk (CM) formula. These formulas were used as the sole milk substitute to breast milk in case of insufficient breastfeeding in high risk infants during the first four months of life. Parents were asked to complete questionnaires at the ages of 1 , 2, 3, 4, and 6 years. At 3 years of age, the group evaluated 133 of the children who were exclusively fed one of the formulas. Although the $\mathrm{pHF}-\mathrm{W}$ and $\mathrm{eHF}-\mathrm{C}$ formulas were protective for the development of eczema, the same was not noted for the development of asthma. Asthma was diagnosed when parents reported three or more episodes of wheezing or nighttime cough without infection, or regular use of asthma medications. Four of $42(10 \%)$ in the CM formula group developed asthma while seven of $31(23 \%)$ in the pHF-W formula group and nine of 31 $(29 \%)$ in the eHF-W formula groups developed asthma. Only two of $29(7 \%)$ in the eHF-C formula group developed asthma. The same trend was seen in those infants who were breastfed and supplemented with a study formula. ${ }^{70}$ Similarly, at 6 years of age, there was no preventive effect of any of the formulas on the cumulative incidence of asthma. ${ }^{71}$ More studies are needed to determine if any of the hydrolyzed formulas have an effect on the incidence of asthma in later life. No studies have investigated the use of amino-acid based formulas on the prevention of atopic diseases. ${ }^{58}$

\section{Solid food introduction and asthma development}

A few studies have examined the effect or the timing of introduction of complementary foods on the development of atopic conditions. The AAP has suggested that solid foods be delayed until four to six months of age.$^{58}$ Some studies have questioned some of these recommendations. In 1983, Fergusson et al tried to establish the relationship of a milk diet and solid feeding practices during the first four months of life to rates of early childhood asthma. There was no evidence to suggest an association between early solid food introduction and childhood asthma. Of the 802 children who had been introduced to solid food during the first four months of life, 58 (7.2\%) developed asthma compared with 19 of 308 $(6.2 \%)$ children who had not been given solid food. ${ }^{72}$ In the UK, guidelines recommended exclusive breast feeding for the first four to six months with introduction of solids thereafter, egg, milk, and fish being added to the diet last. With a large 
prospective birth cohort, the researchers sought to determine if this delayed introduction of foods had any effect on transient wheezing or preschool wheezing by 5.5 years of age. Over 600 children were recruited as infants and followed. Questionnaires on wheezing were administered to mothers yearly. Preschool wheezing was defined as wheezing in year five and additionally in one of the preceding years or wheezing in each of the years one to four. Transient wheezing was defined as wheezing in any of the first two years, but not in year four or five. Within the first year of life, rice, fruit, vegetables, and cereal were given earlier than meat, fish, and milk. Egg was fed later with a median of eight months. Almost $19 \%$ of the study group developed preschool wheezing, while 30\% developed transient wheezing indicating that delayed introduction of foods was not protective of wheezing. When comparing children who delayed introduction of solids ( $>$ three months), milk ( $>$ six months), egg (> eight months), and/or fish ( $>$ six months) to children who did not delay these food introductions, there was no significant difference in the development of transient wheezing or preschool wheezing. ${ }^{73}$ The same group found similar results in the Influences of Lifestyle-Related Factors on the Immune System and the Development of Allergies in Childhood study which was a population-based, prospective birth cohort study involving over 2,000 infants from Germany followed up to six years of age. They found that the prevalence of doctordiagnosed asthma did not differ between children who were introduced to solids within the first 4 months of life, between months 4 and 6 , and after 6 months. ${ }^{74}$

The AAP also recommended that infants considered at high risk of developing atopic diseases should avoid egg until two years of age and avoid peanuts tree nuts and fish until three years of age ${ }^{59}$ A prospective, randomized, controlled trial of food avoidance in infancy studied whether delaying the introduction of these foods would reduce the risk of atopic disease development. All children entered into the study had at least one parent with documented atopy. Asthma was defined as physician-documented lower respiratory disorder with reversible bronchospasm, occurring at least twice and unassociated with other possible conditions. The prophylactic-treated group consisted of infants whose mothers avoided cow's milk, egg, and peanut in the last trimester of pregnancy and lactation and who, themselves, avoided cow's milk until 1 year of age, egg until 2 years of age, and peanut and fish until three years of age. These 59 infants were compared to a control group of 106 infants and both groups were followed until 7 years of age. Although the prophylactic treated group had less food allergy at 1 year of age, the cumulative and period prevalence of asthma, allergic rhinitis, and atopic dermatitis were similar in both groups at seven years of age. ${ }^{75}$ Currently, the AAP continues to suggest delaying solid food introduction until four to six months of age, but the group believes that there is no convincing evidence to delaying introduction beyond six months, including highly allergenic foods such as egg, fish, or peanut containing products. ${ }^{58}$

\section{Management of food allergy}

The most important part of the management of food allergy is complete avoidance of the implicated food(s). Currently, this is the only proven form of prophylactic management. Unfortunately, this can be very difficult if the patient is very sensitive to a food allergen, the food is ubiquitous, and/or the food is a hidden ingredient. It is essential to educate patients and their families in closely analyzing food labels to determine if the inciting food allergens are present. ${ }^{15}$ In 2006, the Food Allergen Labeling and Consumer Protection Act went into effect in the United States and required food manufacturing companies to use simple English terms when describing certain regulated food allergens (ie, milk, egg, wheat, soy, peanut, tree nuts, fish, and shellfish). ${ }^{4}$ Families should also be counseled on the risk of cross-contamination at home, other individual's homes, schools, and restaurants. This is also an issue in the food-manufacturing industry because of shared processing equipment. Patients and families should be encouraged to carry medical identification jewelry and be taught the signs, symptoms, and management of anaphylaxis including the use of a self-injectable epinephrine device and the activation of emergency services. Prophylactic medications such as antihistamines, oral cromolyn, or oral corticosteroids have not been shown to be effective in preventing severe, life-threatening reactions and may actually mask a less severe reaction. ${ }^{15}$ Families should also be advised to take advantage of resources which provide extensive educational materials, such as The Food Allergy and Anaphylaxis Network (Fairfax, VA; http://foodallergy.org). ${ }^{76}$ As most food allergies are outgrown, it is essential that after the diagnosis the patient be followed closely by the allergist to determine if and when the food(s) may be reintroduced into his or her diet. Frequently, the best way to determine if the food can be reintroduced is with an OFC. Depending on the underlying disease and food allergen, intervals for repeat OFCs can be determined. Prior to the OFC, ancillary tests may be performed including repeat prick skin testing and serum food-specific IgEs to establish whether the patient can safely undergo the procedure. ${ }^{15}$

Food allergic children with co-morbid asthma should be maintained on preventive asthma medications and followed closely to maintain well-controlled asthma, particularly in the event of an accidental ingestion and reaction. 


\section{Conclusion}

Food allergy and asthma frequently co-exist. Since asthma may predispose a patient to suffer a life-threatening reaction to a food, aggressive asthma management is essential. Although food allergy is rarely the etiology of asthma, it is important to monitor food allergic patients because they have a higher risk of developing asthma later in life and these patients may have more severe asthma. Although the ingestion of food allergens rarely leads to only respiratory reactions, cough and wheeze can be seen with food allergen inhalation. More research is needed to determine if certain modifications to the maternal and infant diet may modify atopic outcomes, including food allergy and asthma. It is essential to educate patients and their families on the management of food allergy and to review their risk of developing co-morbid asthma.

\section{Disclosure}

The authors report no conflicts of interest in this work.

\section{References}

1. Sicherer SH, Teuber S. Current approach to the diagnosis and management of adverse reactions to foods. J Allergy Clin Immunol. 2004;114(5):1146-1150

2. Rona RJ, Keil T, Summers C, et al. The prevalence of food allergy: a meta-analysis. J Allergy Clin Immunol. 2007;120(3):638-646.

3. Branum AM, Lukas SL. Food allergy among U.S. children: trends in prevalence and hospitalizations. NCHS Data Brief. 2008;(10):1-8.

4. Sicherer SH, Sampson HA. Food allergy. J Allergy Clin Immunol. 2006;117 Suppl 2:S470-S475.

5. Skirpak JM, Matsui EC, Mudd K, Wood RA. The natural history of IgE-mediated cow's milk allergy. J Allergy Clin Immunol. 2007;120(5):1172-1177.

6. Savage JH, Matsui EC, Skripak JM, Wood RA. The natural history of egg allergy. J Allergy Clin Immunol. 2007;120(6):1413-1417.

7. Keet CA, Matsui EC, Dhillon G, Lenehan P, Paterakis M, Wood RA. The natural history of wheat allergy. Ann Allergy Asthma Immunol. 2009;102(5):410-415.

8. Savage JH, Kaeding AJ, Matsui EC, Wood RA. The natural history of soy allergy. J Allergy Clin Immunol. 2010;125(3):683-686.

9. Skolnick HS, Conover-Walker MK, Koerner CB, Sampson HA, Burks W, Wood RA. The natural history of peanut allergy. J Allergy Clin Immunol. 2001;107(2):367-374.

10. Fleischer DM, Conover-Walker MK, Matsui E, Wood RA. The natural history of tree nut allergy. J Allergy Clin Immunol. 2005; 116(5):1087-1093.

11. Sampson HA. Food allergy. JAllergy Clin Immunol. 2003;111(2 Suppl 2): S540-S547.

12. Sicherer SH. Clinical aspects of gastrointestinal food allergy in childhood. Pediatrics. 2003;111(6):1609-1616.

13. Sampson HA. Anaphylaxis and emergency treatment. Pediatrics. 2003;111(6):1601-1608

14. Bock SA. Diagnostic evaluation. Pediatrics. 2003;111(6) 1638-1644.

15. American College of Allergy, Asthma, and Immunology. Food allergy: a practice parameter. Ann Allergy Asthma Immunol. 2006;96(3 Suppl 2): S1-S68.

16. Beausoleil JL, Spergel JM. Food intolerance and childhood asthma: what is the link? Pediatr Drugs. 2007;9(3):157-163.

17. Sampson HA. Update on food allergy. J Allergy Clin Immunol. 2004;113(5):805-819.
18. Sporik R, Hill DJ, Hosking CS. Specificity of allergen skin testing in predicting positive open food challenges to milk, egg, and peanut in children. Clin Exp Allergy. 2000;30(11):1540-1546.

19. Sampson HA, Ho DG. Relationship between food-specific IgE concentration and risk of positive food challenges in children and adolescents. J Allergy Clin Immunol. 1997;100(4):444-451.

20. Sampson HA. Utility of food-specific IgE concentrations in predicting symptomatic food allergy. J Allergy Clin Immunol. 2001; 107(5):891-896.

21. Perry TT, Matsui EC, Conover-Walker MK, Wood RA. The relationship of allergen-specific IgE levels in serum for the outcome of oral food challenges. J Allergy Clin Immunol. 2004;114(1):144-149.

22. Celik-Bilgili S, Mehl A, Verstege A, et al. The predictive value of specific immunoglobulin E levels in serum for the outcome of oral food challenges. Clin Exp Allergy. 2005;35(3):268-273.

23. Nowak-Wegrzyn A, Assa'ad AH, Bahna SL, Bock SA, Sicherer SH, Teuber SS; Adverse Reactions to Food Committee of the American Academy of Allergy, Asthma, and Immunology. Work group report: oral food challenge testing. J Allergy Clin Immunol. 2009;123 Suppl 6:S365-S383.

24. American Lung Association. Epidemiology and Statistics Unit, Research and Program Services Division: trends in asthma morbidity and mortality. Feb, 2010. Available from: http://www.lungusa.org/ finding-cures/grant-opportunities/trend-reports/asthma-trend-report pdf. Accessed Jun 6, 2010.

25. World Health Organization. Global surveillance, prevention, and control of chronic respiratory diseases: a comprehensive approach. 2007. Available from: http://www.who.int/respiratory/asthma. Accessed Mar 30, 2010.

26. Centers for Disease Control. Surveillance for asthma - United States, 1960-1995. MMWR CDC Surveill Summ. 1998;47(1):1-28.

27. Oehling A, Baena Cagnani CE. Food allergy and child asthma. Allergol Immunopathol (Madr). 1990;8(1):7-14.

28. Wang J, Visness CM, Sampson HA. Food allergen sensitization in inner-city children with asthma. J Allergy Clin Immunol. 2005;115(5):1076-1080

29. Ker J, Hartert TV. The atopic march: what's the evidence? Ann Allergy Clin Immunol. 2009;103(10):282-289.

30. Priftis KN, Mermiri D, Papadopoulou A, Papadopoulos M, Fretzayas A, Lagona E. Asthma symptoms and bronchial reactivity in school children sensitized to food allergens in infancy. J Asthma. 2008;45(7):590-595.

31. Tariq SM, Matthews SM, Hakim EA, Arshad SH. Egg allergy in infancy predicts respiratory allergic disease by four years of age. Pediatr Allergy Immunol. 2000;11(3):162-167.

32. Schroeder A, Kumar R, Pongracic JA, et al. Food allergy is associated with an increased risk of asthma. Clin Exp Allergy. 2009; 39(2):261-270.

33. Brockow I, Zutavern A, Hoffman U, et al. Early allergic sensitizations and their relevance to atopic diseases in children aged six years: results of the GINI study. J Investig Allergol Clin Immunol. 2009;19(3):180-187.

34. Sampson HA, Medelson LM, Rosen JP. Fatal and near-fatal anaphylactic reactions to food in children and adolescents. $N$ Engl J Med. 1992; 327(6):380-384.

35. Bock SA, Munoz-Furlong A, Sampson HA. Fatalities due to anaphylactic reactions to foods. J Allergy Clin Immunol. 2001;107(1):191-193.

36. Bock SA, Munoz-Furlong A, Sampson HA. Further fatalities caused by anaphylactic reactions to food, 2001-2006. J Allergy Clin Immunol. 2007;119(4):1016-1018.

37. Jarvinen KM, Sicherer SH, Sampson HA, Nowak-Wegrzyn A. Use of multiple doses of epinephrine in food-induced anaphylaxis. $J$ Allergy Clin Immunol. 2008;122(1):133-138.

38. Simpson AB, Glutting J, Yousef E. Food allergy and asthma morbidity in children. Pediatr Pulmonol. 2007;42(6):489-495.

39. Roberts G, Patel N, Levi-Schaffer F, Habibi P, Lack G. Food allergy as a risk factor for life-threatening asthma in childhood: a case controlled study. J Allergy Clin Immunol. 2003;112(1):168-174. 
40. Vogel NM, Katz HT, Lopez R, Lang DM. Food allergy is associated with potentially fatal childhood asthma. J Asthma. 2008;45(10):862-866.

41. Bock SA, Atkins FM. Patterns of food hypersensitivity during sixteen years of double-blind, placebo-controlled food challenges. J Pediatr. 1990;117(4):561-567.

42. Onorato J, Merland N, Terral C, Michel FB, Bousquet J. Placebocontrolled double-blind food challenge in asthma. J Allergy Clin Immunol. 1986;78(6):1139-1146.

43. Novembre E, de Martino M, Vierucci A. Foods and respiratory allergy. J Allergy Clin Immunol. 1988;81(5 Pt 2):1059-1065.

44. James JM, Bernhisel-Broadbent J, Sampson HA. Respiratory reactions provoked by double-blind food challenges in children. Am J Respir Crit Care Med. 1994;149(1):59-64.

45. James JM, Eigenmann PE, Eggleston PA, Sampson HA. Airway reactivity changes in asthmatic patients undergoing blinded food challenges. Am J Respir Crit Care Med. 1996;13(2):597-603.

46. Woods RK, Weiner JM, Abramson M, Thien F, Walters EH. Do dairy products induce bronchoconstriction in adults with asthma? $J$ Allergy Clin Immunol. 1998;101(1):45-50.

47. Dykewicz MS. Occupational asthma: current concepts in pathogenesis, diagnosis, and management. J Allergy Clin Immunol. 2009;123(3):519-528.

48. Brant A. Baker's asthma. Curr Opin Allergy Clin Immunol. 2007;7(2):152-155.

49. Walusiak J, Hanke W, Gorski P, Palczynski C. Respiratory allergy in apprentice bakers: do occupational allergies follow the allergic march? Allergy. 2004;59(4):442-450.

50. James JM. Respiratory manifestations of food allergy. Pediatrics. 2003;111(6):1625-1630.

51. Crespo JF, Pascual C, Dominguez C, Ojeda I, Munoz FM, Esteban MM. Allergic reactions associated with airborne fish particles in IgEmediated fish hypersensitive patients. Allergy. 1995;50(3):257-261.

52. Jones RT, Stark DF, Sussman Gl, Yunginger JW. Recovery of peanut allergens from ventilation filters of commercial airliners [abstract]. J Allergy Clin Immunol. 1996;97(1 Suppl 3):423.

53. Sicherer SH, Furlong TJ, DeSimone J, Sampson HA. Self-reported allergic reactions to peanut on commercial airliners. J Allergy Clin Immunol. 1999;104(1):186-189.

54. Akinbami L; Centers for Disease Control and Prevention National Center for Health Statistics. Asthma prevalence, health care use, and mortality: United States, 2003-05. 2006. Available from: http://www. cdc.gov. Accessed Mar 31, 2010.

55. Zeiger RS. Food allergen avoidance in the prevention of food allergy in infants and children. Pediatrics. 2003;111(6):1662-1671.

56. Kramer MS, Kakuma R. Maternal dietary antigen avoidance during pregnancy or lactation, or both, for preventing or treating atopic disease in the child. Cochrane Database Syst Rev. 2006;(3):CD000133.

57. Willers SM, Wijga AH, Brunekreef B, et al. Maternal food consumption during pregnancy and the longitudinal development of childhood asthma. Am J Respir Crit Care Med. 2008;178(2):124-131.

58. Greer FR, Sicherer SH, Burks AW; American Academy of Pediatrics Committee on Nutrition; American Academy of Pediatrics Section on Allergy and Immunology. Effects of early nutritional interventions on the development of atopic disease in infants and children: the role of maternal dietary restriction, breastfeeding, timing of introduction of complementary foods, and hydrolyzed formulas. Pediatrics. 2008;121(1):183-191.
59. Litonjua AA, Weiss ST. Is vitamin D deficiency to blame for the asthma epidemic? J Allergy Clin Immunol. 2007;120(5)1031-1035.

60. Camargo CA, Rifas-Shiman SL, Litonjua AA, et al. Maternal intake of vitamin D during pregnancy and risk of recurrent wheeze in children at three years of age. Am J Clin Nutr. 2007;85(3)788-795.

61. Wjst M, Dold S. Genes, factor X, and allergens: what causes allergic diseases? Allergy. 1999;54(7):757-759.

62. Gale CR, Robinson SM, Harvey NK, et al. Maternal vitamin D status during pregnancy and child outcomes. Eur J Clin Nutr. 2008;62(1):68-77.

63. American Academy of Pediatrics Committee on Nutrition. Hypoallergenic infant formulas. Pediatrics. 2000;112(2):1203-1207.

64. Kull I, Almqvist C, Lilja G, Pershagen G, Wickman M. Breast-feeding reduces the risk of asthma during the first four years of life. J Allergy Clin Imunol. 2004;114(4):755-760.

65. Gdalevich M, Mimouni D, Mimouni M. Breast-feeding and the risk of bronchial asthma in childhood: a systemic review with meta-analysis of prospective studies. J Pediatr. 2001;139(2):261-266.

66. Matheson MC, Erbas B, Balasuriya A, et al. Breast-feeding and atopic disease: a cohort study from childhood to middle age. J Allergy Clin Immunol. 2007;120(5):1051-1057.

67. Sears MR, Greene JM, Willan AR, et al. Long-term relation between breastfeeding and development of atopy and asthma in children and young adults: a longitudinal study. Lancet. 2002;360(9337):901-907.

68. Elliott L, Henderson J, Northstone K, Chiu GY, Dunson D, London SJ. Prospective study of breast-feeding in relation to wheeze, atopy, and bronchial hypperresponsiveness in the Avon Longitudinal Study of Parents and Children. J Allergy Clin Immunol. 2008;122(1):49-54.

69. Oldaeus G, Anjou K, Bjorksten B, Moran JR, Kjellman NI. Extensively and partially hydrolyzed infant formulas for allergy prophylaxis. Arch Dis Child. 1997;77(1):4-10.

70. von Berg A, Koletzko S, Filipiak-Pittroff B, et al. Certain hydrolyzed formulas reduce the incidence of atopic dermatitis but not that of asthma: three-year results of the German Infant Nutritional Intervention Study. J Allergy Clin Immunol. 2007;119(3):718-725.

71. von Berg A, Filipiak-Pittroff B, Kramer U, et al. Preventive effect of hydrolyzed infant formulas persists until age six years: long-term results from the German Infant Nutritional Intervention study (GINI). J Allergy Clin Immunol. 2008;121(6):1442-1447.

72. Fergusson DM, Horwood LJ, Shannon FT. Asthma and infant diet. Arch Dis Child. 1983;58(1):48-51.

73. Zutavern A, Brockow I, Schaaf B, et al. The introduction of solids in relation to asthma and eczema. Arch Dis Child. 2004;89(4):303-308.

74. Zutavern A, Brockow I, Schaaf B, et al. Timing of solid food introduction in relation to eczema, asthma, allergic rhinitis, and food and inhalant sensitization at the age of six years: results from the prospective birth cohort study LISA. Pediatrics. 2008;121(1):e44-e52.

75. Zeiger RS, Heller S. The development and prediction of atopy in highrisk children: follow-up at age seven years in a prospective randomized study of combined maternal and infant food allergen avoidance. J Allergy Clin Immunol. 1995;95(6):1179-1190.

76. Sicherer SH, Sampson HA. Food allergy. J Allergy Clin Immunol. 2010;125(2 Suppl 2):S116-S1125.
Journal of Asthma and Allergy

\section{Publish your work in this journal}

The Journal of Asthma and Allergy is an international, peer-reviewed open-access journal publishing original research, reports, editorials and commentaries on the following topics: Asthma; Pulmonary physiology; Asthma related clinical health; Clinical immunology and the immunological basis of disease; Pharmacological interventions and

new therapies. Issues of patient safety and quality of care will also be considered. The manuscript management system is completely online and includes a very quick and fair peer-review system, which is all easy to use. Visit http://www.dovepress.com/testimonials.php to read real quotes from published authors.

\section{Dovepress}

Submit your manuscript here: http://www.dovepress.com/journal-of-asthma-and-allergy-journal 